\title{
IMPLEMENTASI KEBIJAKAN PENATAAN PEDAGANG KAKI LIMA DI SENTRA IKAN BULAK KENJERAN KECAMATAN BULAK KOTA SURABAYA
}

\author{
Rizky Wibisono \\ Fakultas Ilmu Sosial dan Ilmu Politik, Universitas Pembangunan Nasional "Veteran” Jawa Timur, \\ rizkywibi2@gmail.com \\ Tukiman \\ Fakultas Ilmu Sosial dan Ilmu Politik, Universitas Pembangunan Nasional "Veteran” Jawa Timur, \\ tukiman_upnjatim@yahoo.com
}

\begin{abstract}
Abstrak
Keberadaan Pedagang Kaki Lima (PKL) di Indonesia sering menjadi sorotan publik, khususnya dalam bidang tata kelola ruang kota. Untuk itu, dibutuhkan kebijakan pemerintah dalam menata dan mengatur keberadaan PKL, khususnya di Kota Surabaya. Salah satu upaya Pemerintah Kota Surabaya adalah dengan melakukan penataan pedagang kaki lima di Sentra Ikan Bulak tujuannya adalah mengatur atau menertibkan untuk berjualan yang legal, lebih tertib, teratur. Ditambah dengan fasilitas dan kemudahan yang diberikan secara gratis di Sentra Ikan Bulak. Tetapi setelah dilihat di lapangan program penataan PKL tidak berjalan dengan maksimal, itu bisa dilihat dengan kondisi Sentra Ikan Bulak yang sepi ditinggal para pedagang. Oleh karena itu, perlu diketahui bagaimana implementasi kebijakan penataan PKL di Sentra Ikan Bulak Kenjeran, Kecamatan Bulak Kota Surabaya. Penelitian ini merupakan penelitian deskriptif kualitatif dengan teknik pengumpulan data berupa observasi, wawancara dan dokumentasi. Tujuan penelitian ini adalah untuk mendeskripsikan implementasi kebijakan penataan PKL di sentra Ikan Bulak Kenjeran Kecamatan Bulak Kota Surabaya yang dapat dilihat dari tiga faktor yaitu perspektif kepatuhan, keberhasilan, kepuasan penerima manfaat. Berdasarkan hasil penelitian menunjukkan bahwa implementasi kebijakan penataan PKL di Sentra Ikan Bulak Kenjeran Kecamatan Bulak Kota Surabaya dilihat dari tiga faktor perspektif kepatuhan, keberhasilan, kepuasan penerima manfaat belum semua faktor berjalan dengan lancar, dikarenakan masih ada tingkat kepatuhan yang belum dipatuhi oleh pedagang yaitu mengenai jumlah pedagang dan jenis barang yang diperdagangkan oleh pedagang
\end{abstract}

Kata Kunci: Implementasi Penataan, Pedagang Kaki Lima, Sentra Ikan Bulak

\begin{abstract}
The existence of street vendors (PKL) in Indonesia often become the public spotlight, particularly in the areas of governance of urban space. For that, it takes the role of government in managing and organizing the presence of street vendors, especially in the city of Surabaya. one of the efforts of the Surabaya City government is to arrannge street vendors in bulak fish center the goal is to arrange or discipline to sell a legal, more orderly. Coupled with the facilities and facilities provided free og charge at the bulak fish center. But after being seen in the field of structuring program of street hawkers do not walk with the maximum, it can be seen with the condition of a sparse bulak fish center left behind by traders. Therefore need to know how the implementation of the policy of structuring of street vendors in kenjeran bulak fish center, districts bulak city of Surabaya. This research is descriptive qualitative data collection techniques such as observation, interviews and documentation. The purpose of this study is to describe the implementation of the policy of oragnizing of street vendors in bulak fish center sub-district bulak city of Surabaya, which can be seen from three factors of compliance, fluency, satisfaction Based of result of research indicate that the implementation of the policy of organizing of street vendors in the bulak fish center kenjeran district bulak city Surabaya seen from three factors of compliance, fluency, satisfaction not all factors run smoothly, because there is still a level of compliance that has not been obeyed by street vendors that is about the amount traders and types of goods traded by traders.
\end{abstract}

Keywords: implementation of the organizing, street vendors, bulak fish center

\section{PENDAHULUAN}

Negara-negara berkembang saat ini sedang melaksanakan pembangunan dalam rangka mencapai kesejahteraan masyarakat, demikian juga negara Indonesia dimana dalam melaksanakan pembangunan tersebut mempunyai tujuan untuk meningkatkan taraf 
hidup dan kesejahteraan seluruh rakyat serta meletakkan landasan yang kuat bagi pembangunan berikutnya.

Sebagai kota yang tengah bergulir menjadi mega urban, sudah tentu perkembangan kota besar seperti Surabaya tidak bisa dibiarkan tumbuh liar, semrawut dan tidak terciptanya ketertiban sosial. Di kota-kota besar, ketidaktertiban tercipta dari berbagai macam hal. Diantaranya perkembangan kota secara pesat yang tidak disertai dengan pertumbuhan kesempatan kerja yang memadai. Hal tersebut mengakibatkan kota-kota besar menghadapi berbagai macam problema sosial yang pelik.Hal ini menjadi ciri umum kebanyakan perkotaan di negara-negara berkembang termasuk Indonesia.Pada suatu masyarakat dimana pertumbuhan ekonomi negara menganut rezim ekonomi kapitalis, maka yang terjadi adalah kontraksi antara pasar tenaga kerja dan pertumbuhan pencari kerja. Bila hal tersebut yang terjadi, maka rakyat kecil berusaha mencari cara lain untuk bisa mempertahankan hidupnya. Seperti keadaan para pedagang kaki lima yang merupakan suatu kegiatan perekonomian rakyat kecil.

Keberadaan pedagang kaki lima (PKL) di Indonesia sering menjadi sorotan publik, khususnya dalam bidang tata kelola ruang kota. Hal ini dikarenakan keberadaan para PKL merusak estetika kota dengan kesemrawutan dan kekumuhannya. Menurut pengertiannya dalam Perda Kota Surabaya No.17 Tahun 2003 tentang Penataan PKL, Pedagang Kaki Lima adalah pedagang yang menjalankan kegiatan usahanya dalam jangka waktu tertentu dengan mempergunakan sarana atau perlengkapan yang mudah dipindahkan, dibongkar pasang dan mempergunakan lahan fasilitas umum sebagai tempat usahanya. Karena berjualan ditempat-tempat yang menjadi fasilitas umum, fenomena Pedagang Kaki Lima mampu menghambat lalu lintas dan merampas hak-hak pejalan kaki.

Fenomena PKL banyak dijumpai di kota-kota besar di Indonesia.Salah satunya di Kota Surabaya.sebagai kota metropolitan, para PKL membawa dampak bagi masyarakat pedesaan atau warga disekitar Surabaya untuk melakukan urbanisasi, tujuannya adalah mencoba mencari rejeki di Surabaya dengan membuka usaha atau mencari pekerjaan. Tidak banyak diantara mereka yang berhasil mendapatkan pekerjaan yang mapan setelah pindah ke Surabaya.Salah satu jalan yang kemudian mereka tempuh adalah membuka usaha menjadi Pedagang Kaki Lima (PKL), meskipun dengan modal dan keterampilan yang minim.

Salah satu sektor yang mempunyai potensi berkumpulnya PKL adalah wisata rekreasi. Salah satu tempat wisata rekreasi yang cukup ramai, murah dan meriah di Kota Surabaya adalah pantai Ria Kenjeran, di Kecamatan Bulak. Pantai Ria Kenjeran adalah salah satu destinasi wisatawan lokal maupun regional ketika berwisata di Surabaya. berada dibagian timur Surabaya, Pantai Ria Kenjeran ini merupakan pantainya arek-arek Suroboyo dengan beberapa fasilitas yang beraneka ragam mulai dari olah raga hingga cinderamata khas Surabaya (www.surabaya.go.id).

Dari ramainya wisatawan yang datang ke pantai Ria Kenjeran tersebut menarik minat masyarakat untuk menjadi PKL. Semakin hari jumlah PKL yang ada di wisata pantai kenjeran semakin banyak.Hal ini baik secara langsung dan tidak langsung mengganggu kenyamanan para pengguna jalan. Seperti para pedagang kaki lima yang ada di sepanjang jalan menuju Taman Hiburan pantai Kenjeran, di jalan kenjeran Lama, Kecamatan Bulak. Di Kecamatan Bulak ini banyak pedagangpedagang yang membangun kios makanan dan minuman maupun kios ikan asap, bahkan ada pedagang makanan dan minuman yang membangun kios semi permanen di atas bantaran sungai. Dampaknya, selain menimbulkan pencemaran sungai maupun pantai, karena sampah yang dihasilkan dari sisa-sisa pembuangan makanan dan minuman. Juga mengganggu keindahan dan tata kelola kota Surabaya, karena menempati wilayah-wilayah yang dilarang oleh pemerintah.

\section{METODE}

Penelitian ini merupakan penelitian deskriptif kualitatif. Menurut Sugiyono (2015:15), menjelaskan bahwa metode penelitian kualitatif merupakan metode penelitian yang berlandaskan pada filsafat positivisme, digunakan untuk meneliti pada kondisi obyek yang alamiah, (sebagai lawanya adalah eksperimen) dimana peneliti adalah sebagai instrumen kunci, pengambilan sampel sumber datadilakukan secara purposive dan snowbaal, teknik pengumpulan dengan trianggulasi, analisis data bersifat induktif/kualitatif, dan hasil penelitian kualitatif lebih menekan makna dari pada generalisasi.Penentuan fokus penelitian menurut Moleong (2007: 386) memiliki dua tujuan pertama, penetepan fokus membatasi studi yang berarti bahwa dengan adanya fokus maka penentuan tempat penelitian menjadi lebih layak. Kedua, penentuan fokus maka secara efektif menentukan kriteria inklusi-eksekusi untuk menyaring informasi yang masuk.Berdasarkan rumusan masalah dalam penelitian ini, maka yang menjadi fokus dalam penelitian ini adalah:

1. Pengaturan waktu kegiatan PKL, dengan sasaran kajian: waktu atau jam untuk berjualan para PKL hingga jam tutup para PKL

2. pengaturan jumlah PKL, dengan sasaran kajian: jumlah stan dan jumlah PKL yang menempati Sentra Ikan Bulak 
3. pengaturan jenis barang yang diperdagangkan PKL, dengan sasaran kajian: jenis barang apa saja yang diperdagangkan

4. pengaturan alat peraga PKL, dengan sasaran kajian: penyediaan alat untuk berjualan para PKL

\section{HASIL DAN PEMBAHASAN}

Sesuai dengan fokus penelitian berpedoman pada Peraturan Daerah dalam penataan PKL, hal ini ada 4 fokus penelitian yaitu waktu kegiatan usaha PKL, jumlah PKL, jenis barang yang diperdagangkan PKL, alat peraga PKL.

\section{Waktu Kegiatan PKL}

Pedagang yang berjualan di sentra ikan bulak kenjeran menjual hasil olahan ikan atau olahan hasil laut yang diberi batas waktu berjualan.Berdasarkan Peraturan Daerah Kota Surabaya Nomor 17 tahun 2003 tentang Penataan dan Pemberdayaan Pedagang Kaki Lima.Sesuai dengan kewenangan yang sudah dibuat oleh pemerintah daerah yaitu waktu berdagang PKL.Pemerintah daerah sudah membuat batasan waktu berdagang untuk para PKL agar teratur untuk berdagang.Dan pengaturan waktu yang dibuat oleh pemerintah ini sudah bisa diterima dan dilakukakan dengan baik oleh para PKL di Sentra Ikan Bulak. Dengan adanya waktu berdagang yang ditentukan membuat Sentra Ikan Bulak teratur untuk menjalankan operasional jual beli.

\section{Jumlah PKL}

Hasil temuan lapangan mengenai jumlah PKL di Sentra Ikan Bulak menunjukkan bahwa Sentra Ikan Bulak masih sepi pedagang dan tidak sesuai dengan apa yang di atur oleh pemerintah. Para pedagang tidak memenuhi stan yang sudah disediakan oleh pemerintah tersebut. Menurut data yang diperoleh peneliti, jumlah pedagang yang aktif hanyalah 55 pedagang.

Berdasarkan Peraturan Daerah Kota Surabaya Nomor 17 tahun 2003 tentang Penataan dan Pemberdayaan Pedagang Kaki Lima.Sesuai dengan kewenangan yang sudah dibuat oleh pemerintah daerah yaitu Jumlah PKL. Pemerintah sudah menyediakan tempat berdagang sebanyak 212 stan dengan harapan bisa terisi semuaPengaturan jumlah pedagang kaki lima di Sentra Ikan Bulak dari banyaknya stan yang sudah disediakan, yaitu sampai 212 stan, yang aktif berdagang hanya berjumlah kurang lebih 55 pedagang, sangat jauh dengan apa yang diharapkan oleh pemerintah daerah yang mempunyai keinginan sentra ikan bulak dengan jumlah stan 212 terisi semua.

\section{Jenis Barang Dagangan PKL}

Pedagang yang berdagang di sentra ikan bulak kenjeran Surabaya dikhususkan atau diperuntukkan untuk menjual hasil perikanan, seperti penuturan ibu walikota bu Risma yang ada di media yaitu Sentra Ikan Bulak seharusnya diperuntukkan sebagai pusat pengolahan dan pemasaran hasil perikanan (m.liputan6.com).

Tetapi jika dilihat di lapangan, yang berjualan di sentra ikan bulak tidak hanya pedagang hasil olahan laut melainkan ada yang berjualan selain olahan laut seperti ayam goreng, nasi goreng dan lain-lain.

\section{Alat Peraga PKL}

Alat peraga pedagang kaki lima dalam hal ini adalah alat yang digunakan untuk berdagang, ada yang sudah disediakan oleh pemerintah melalui dinas pertanian dan masih ada yang swadaya dari para pedagang. Alat yang disediakan oleh pemerintah daerah adalah alat untuk pengasapannya saja dan stan-stan untuk tempat berjualan. Alat peraga yang swadaya dari pedagang sendiri adalah pedagang yang selain berjualan olahan hasil laut seperti pedagang ayam goreng, bebek goreng dan lain - lain yang selain berdagang olahan laut.

\section{PENUTUP}

\section{Simpulan}

Berdasarkan analisis dalam pembahasan maka dalam penelitian mengenai Implementasi kebijakan penataan pedagang kaki lima di sentra ikan bulak kenjeran dalam 4 fokus yaitu waktu berdagang PKL, jumlah PKL, jenis barang dagangan PKL, alat peraga PKL.Dapat disimpulkan sebagai berikut.

Program penataan PKL merupakan sebuah program yang dibuat oleh Pemerintah Kota Surabaya untuk menciptakan lingkungan perkotaan yang lebih bersih, tertib dan aman bagi seluruh elemen masyarakat Kota Surabaya, khususnya wilayah Kecamatan Bulak dan sekitarnya.

Dilihat dari faktor kepatuhan, implementasi program penataan PKL di Kecamatan Bulak Kota Surabaya sudah berjalan dengan lancar akan tetapi masih ada kejanggalan mengenai kepatuhan untuk melakukan penataan karena tidak semua pedagang mau dipindahkan ke tempat yang lebih bersih aman dan nyaman. Dilihat dari faktor kelancaran juga sudah baik karena waktu aparat pemerintah dan Satpol PP melakukan penataan para pedagang tidak melakukan perlawanan dan penataan berjalan dengan lancar, namun setelah penataan berjalan 2 bulan, para PKL masih tetap berdagang di pinggir jalan. Keberhasilan program penataan juga didukung oleh kepuasan penerima manfaat, untuk menjadikan para PKL puas dengan implementasi yang dilakukan, Pemerintah Daerah membuat suatu tempat untuk menampung para 
PKL yang semrawut di pinggir jalan. Dengan cara ini bisa membuat para PKL pindah ke tempat yang sudah disediakan oleh pemerintah daerah dan para PKL bisa merasa puas dengan tempat yang sudah disediakan Pemerintah Daerah.

Sesuai dengan data yang diperoleh dan melihat tujuan dilakukannya penelitian ini, maka dapat penliti simpulkan bahwa bahwasannya, program penataan pedagang kaki lima di sentra ikan bulak, kecamatan bulak kota Surabaya yang dilakukan berdasarkan Perda Kota Surabaya No. 17 tahun 2003 tentang penataan dan pemberdayaan pedagang kaki lima berjalan dengan maksimal, terarah dan tepat sasaran sesuai dengan maksud dan tujuan utama dari program tersebut. Namun masakah baru muncul setelah penataan dilakukan. Yang pada awalnya para pedagang setuju untuk pindah di sentra ikan bulak, dalam beberapa bulan setelah penataan, beberapa dari pedagang tersebut mulai meninggalkan sentra ikan bulak dan memilih untuk berjualan kembali di tepi - tepi jalan, seperti pada lokasi awal mereka dalam berjualan, yakni disepanjang jalan di sekitar kawasan THP (Tempat Hiburan Pantai) Kenjeran.

\section{Saran}

Berdasarkan kesimpulan diatas dan sesuai hasil penelitian di lapangan mengenai implementasi program penataan PKL di Kecamatan Bulak Kota Surabaya, penlis memberikan beberapa saran yang diharapkan dapat menjadi alternatif dalam membantu memecahkan masalah ataupun menyempurnakan implementasi kebijakan pada masa yang akan datang. Adapun saran yang dapat disampaikan penulis adalah sebagai berikut:

1. Untuk kewenangan yang sudah terimplementasi seperti waktu berdagang PKL harusnya kebijakan tersebut dipertahankan lagi akan tetapi seharusnya pemerintah daerah juga memberi kelonggaran waktu untuk berdagang PKL agar pedagang betah berjualan di Sentra Ikan Bulak.

2. Untuk kewenangan yang belum terimplementasi seperti jumlah pedagang PKL, dikarenakan para pedagang tidak mau pindah ke SIB dengan macam alasan. Seharusnya pemerintah sering mengadakan sosialisasi kepada para pedagang akan manfaatnya dibangunkan SIB untuk pedagang. Dan pemerintah sering mengadakan berbagai macam kegiatan yang bertujuan untuk mempromosikan keberadaan Sentra Ikan Bulak.

3. Kemudian untuk kewenangan selanjutnya adalah jenis barang dagangan, penulis mempunyai saran agar jenis barang dagangan bisa bervariasi dan nama sentra ikan bulak diganti agar semua PKL bisa masuk atau bisa berjualan.
4. Untuk kewenangan mengenai alat peraga PKL penulis mempunyai saran untuk pemerintah agar selalu memantau alat peraga pedagang agar jika alat peraga pedagang ada yang rusak, maka pemerintah bisa langsung menggantinya dengan baru. Dan seharusnya pemerintah daerah memberikan alat peraga tidak ke pedagang ikan asap saja melainkan ke pedagang pengrajin pernak - pernik dari kerang semacam etalase untuk menyimpan pernak - pernik yang pedagang buat

\section{DAFTAR PUSTAKA}

Agustino, Leo. 2008. Dasar-Dasar Kebijakan Publik. Bandung: Alfabeta.

Moleong, L. J. 2010. Metodologi Penelitian Kualitatif, Bandung: Remaja Rosdakarya.

Peraturan Daerah Kota Surabaya Nomor 17 Tahun 2003 Tentang Penataan dan Pemberdayaan Pedagang Kaki Lima.

Sentra Ikan Bulak Sepi Pengunjung http://m.liputan6.com/regional/read/2474527/sentraikan-bulak-sepi-penjual-risma-ultimatum-lurah-dancamat diakses tanggal 19 Januari 2017.

Sugiyono. 2015. Memahami Penelitian Kualitatif. Bandung: Alfabeta.

Tangkilisan, Hesel, Nogi, 2003. Kebijakan Publik. Yogyakarta: Balaiurang.

Walikota Resmikan Sentra Ikan Bulak http://www.surabaya.go.id/pemerintahan/1229walikota-resmikan-sentra-ikan-bulak diakses tanggal 18 Januari 2017. 